\title{
Advances of Non-Iron Metal Nanoparticles in Biomedicine
}

\author{
Anroop B. Nair ${ }^{1}$, Mohamed A. Morsy ${ }^{1,2}$, Pottathil Shinu ${ }^{3}$, Sabna Kotta ${ }^{4}$, Mithra Chandrasekaran ${ }^{5}$, M. Abu Tahir ${ }^{6}$ \\ ${ }^{1}$ Department of Pharmaceutical Sciences, College of Clinical Pharmacy, King Faisal University, Al-Ahsa, Saudi Arabia; \\ ${ }^{2}$ Department of Pharmacology, Faculty of Medicine, Minia University, El-Minia, Egypt; ${ }^{3}$ Department of Biomedical Sciences, \\ College of Clinical Pharmacy, King Faisal University, Al-Ahsa, Saudi Arabia; ${ }^{4}$ Department of Pharmaceutics, Faculty of \\ Pharmacy, King Abdulaziz University, Jeddah, Saudi Arabia; ${ }^{5}$ Research and Development, Pfizer Healthcare India Pvt. Ltd, \\ Kancheepuram, India; ${ }^{6}$ Formulation \& Development, Steril-gene life sciences, Puducherry, India
}

Corresponding authors: Dr. Anroop B. Nair, Department of Pharmaceutical Sciences, College of Clinical Pharmacy, King Faisal University, Al-Ahsa 31982, Saudi Arabia; TEL: 966-536-219-868; email: anair@kfu.edu.sa; Dr M. Abu Tahir, Formulation \& Development, Steril-gene life sciences, Puducherry, India; Mobile TEL: (+91)-8197270245; email: abu20friend@gmail.com

Received, November 7, 2020; Revised, January 20, 2021; Accepted, January 21, 2021; Published, January 26, 2021

\begin{abstract}
Metal nanoparticles (MNPs) comprise nanoparticles originating from metallic elements with additional properties inherent to metal ions. MNPs found applications in various fields such as electronics, optics, mechanics, physics, etc. There are many reviews on iron MNPs for biomedical applications. Hence, in this review, we focus on non-iron MNPs and their vivid biomedical applications. Here, we review the applications of non-iron MNPs in biomedicine such as drug delivery, gene delivery, anticancer activity, antimicrobial activity, tissue engineering, bioimaging, and photodynamic and photothermal therapies.
\end{abstract}

\section{INTRODUCTION}

The nano-size range (1-1000 nm) of nanoparticles (NPs) facilitates their characteristic properties when compared to larger particles [1]. Further, their unique physiochemical properties are due to the large surface-volume ratio resulting from the nano-size $[2,3]$. The properties of NPs can be tuned to the desired one by controlling the size range [4].

In addition, the metal nanoparticles (MNPs), NPs developed from metals, have distinct physicochemical and biological properties [5]. Interestingly, their properties are entirely different from the bulk metal that leads to the investigation in various fields [6]. The importance of these NPs in biomedicine arises from their capability of interaction with the biological cell membrane and intracellular molecules; thereby expediting the treatment and diagnosis of various disease conditions [2]. NPs can be generally classified into organic and inorganic NPs. Organic NPs include micelles, dendrimers, liposomes, and polymeric NPs. While quantum dots, fullerenes, and MNPs come under inorganic NPs. Micelle consists of polymers or lipids, which are mainly used for enclosing hydrophobic drugs. In an aqueous media, the hydrophobic part of the micelle goes inside, facing the hydrophobic part outside forming a hydrophobic core. Liposome NPs composed of lipid bilayers, hydrophilic drugs are enclosed in the core of the liposome and the hydrophobic one enclosed within the lipid layers. Dendrimers are branched structures with a central core, inner and outer shell. In biomedicine, polyamidoamine derived dendrimer, called PAMAM dendrimer is the most interesting one. Polymeric NPs derived from natural or synthetic polymers that enclose the drug within the core, covalently linked or adsorbed on the surface, or entrapped or dissolved with the NP structure. Quantum dots are semiconductor material in the nano-size with luminescent properties made from silicon or germanium or from $\mathrm{CdSe} \mathrm{PbSe}, \mathrm{CdTe}$, and $\mathrm{PbS}$. They are mainly used as fluorescent probes in biomedicine. Fullerenes are allotropes of carbon with a ball shape. Among fullerenes, buckminsterfullerenes, composed of 60 carbons is the current focus of research.

MNPs mainly include NPs comprising of noble metals (silver, gold, and platinum) and magnetic metals (iron, cobalt, manganese, etc.). Among these, iron oxide NP is the most commonly investigated one owing to its excellent properties of biocompatibility, biodegradability, and ease of synthesis [5-7]. Other than a single metal, a combination of two metals (bimetallic), and metal oxides are also investigated for their biomedical applications. The expansion of 
research in MNPs occurs due to their wide range of applications in drug delivery, biosensing, bioimaging, antibacterial activity, etc. [1-3,5-8]. The biocompatibility and ease of conjugation with different agents (drugs, peptides, antibodies, etc.) lead to the exploration of MNPs in the field of biomedicine [3].

In the field of nanotechnology, MNPs have their own position owing to their unique physical, chemical, and biological properties. MNPs show good mechanical strength, magnetic properties, optical properties such as enhance Rayleigh scattering, surface-enhanced Raman scattering, and strong plasma absorption; these all lead to their exploration in various fields.

Thus, owing to the high significance and interest in non-iron MNPs, we present a review of the advances in the understanding of their types, properties, methods of synthesis, safety profile, and biomedical applications.

\section{TYPES OF MNPs}

\section{Metal-ion NPs}

This category comprises of NPs that originated from the metal ion itself. These include ions of $\mathrm{Ag}, \mathrm{Au}, \mathrm{Pt}$, $\mathrm{Ni}, \mathrm{Cu}$, etc. In the case of AuNPs, their unique physicochemical properties made them suitable for various applications in biomedicine. Apart from this, their ability to interact with functional groups such as amines and thiols allows surface functionalization, which results in targeting function. Au being a noble metal, AuNPs are inert with good biocompatibility. AgNP is another noble MNP with extensive investigations in biomedicine. Similar to AuNP, AgNP possesses unique properties such as high electrical conductivity, thermal conductivity, chemical stability, etc. Other than these properties, the antimicrobial potential of $\mathrm{Ag}$ is of great importance [1,9]. CuNPs have high electrical conduction and good biocompatibility with antimicrobial activity; hence, they applied in the electronic and medical fields [5]. The free radical scavenging ability of PtNPs can be employed for treating oxidative stress-related diseases. They also found applications in the field of bioimaging, cancer therapy, and photothermal therapy [10]. NiNPs are characterized by unique structures and properties. They are mostly investigated for anticancer activity (Figure 1) [11]. AuroLase® therapy by Nanospectra
Biosciences Inc. (Houston, TX) uses focal ablation, which uses gold-silica nanoshells. These nanoshells are around $150 \mathrm{~nm}$ in diameter and accumulate and treat focal lesions in prostate cancer [12]. Further, in another clinical trial, laser-excited gold-silica nanoshells have been found to be effective against prostate cancer. The study used these nanoshells combined with magnetic resonance-ultrasound fusion imaging in 16 patients. A $94 \%$ success rate was found to achieve with the system. Further, no adverse effects were noted in the patients [13].

\section{Metal oxide NPs}

Those NPs, which consist of metal ions in the oxide forms such as $\mathrm{CuO}, \mathrm{ZnO}, \mathrm{TiO}_{2}, \mathrm{CeO}_{2}, \mathrm{SiO}_{2}$, etc. come under this group. $\mathrm{TiO}_{2} \mathrm{NPs}$ are important in photocatalysis because of their characteristic optical and electronic properties. Their brightness and high refractive index lead to their utilization in skincare products [14,15]. ZnO NPs have anticancer and antibacterial activities. The luminescence property of $\mathrm{ZnO}$ NPs has been utilized for bioimaging applications. ZnO NPs are biocompatible with a low toxicity profile. They are capable of maintaining the structural integrity of insulin, by which they pave the way for diabetic therapy. They are included in cosmetic products owing to their strong UV absorption power [16]. Iron oxide NPs have excellent magnetic properties with good biocompatibility and safety profile. They exist in three different oxidation states: $\mathrm{FeO}, \mathrm{Fe}_{2} \mathrm{O}_{3}$, and $\mathrm{Fe}_{3} \mathrm{O}_{4}$. Among these three forms, $\mathrm{Fe}_{3} \mathrm{O}_{4}$ is superparamagnetic in nature and investigated in various fields such as drug and gene delivery, cancer therapy, magnetic resonance imaging, hyperthermia, etc. [17].

$\mathrm{CeO}_{2}$ NPs are found to have enhanced electronic conductivity than their larger particles. They are mainly involved in catalytic function since the surfaces of $\mathrm{CeO}_{2}$ NPs have many defects. The main problem involved with $\mathrm{CeO}_{2} \mathrm{NPs}$ is the particle agglomeration during synthesis at higher temperatures, which causes a reduction in surface area and alters their properties [1,9]. $\mathrm{SiO}_{2} \mathrm{NPs}$ are stable and biocompatible and can be utilized in the field of drug delivery and theranostics. The higher toxicity potential of $\mathrm{CuO}$ NPs limits their applications in biomedicine, while they are employed in the cosmetic and textile industry $[1,9]$.

Feraheme ${ }^{\circledR}$ and Rienso ${ }^{\circledR}$ (AMAG Pharmaceuticals, Inc., Waltham, MA) are USFDA 
approved (2009) formulations of ferumoxytol with FeO NPs. In these, coating with poly glucose sorbitol carboxymethyl ether is provided onto FeO NPs. These are indicated in unsatisfactory oral absorption of iron resulting in anemia or during chronic kidney disease [12]. They have shown prospects for magnetic fluid hyperthermia [18]. Interestingly, these $\mathrm{FeO}$ NPs formulations provide intrinsic immunomodulatory effects [19]. Similarly, another formulation NBTXR3 PEP503 (Nanobiotix, Paris, France) uses hafnium oxide NPs, which when supplied with external radiation cause electron production and cell death. The formulation is presently under clinical trials [20]. Meanwhile, NBTXR3/Hensify (Nanobiotix) contains negativecharged phosphate-coated crystalline hafnium oxide NPs. This formulation got CE Mark approval in April of 2019 [21].

\section{Metal sulfide NPs}

These include MNPs in their sulfide form. CuS, $\mathrm{Ag}_{2} \mathrm{~S}$, etc. metal sulfides show good stability with high fluorescence. The presence of chalcogenide sulfur provides additional functionality. CuS NPs have molecular detection ability and can be used in biosensing. They can also act as photothermal agents. Meanwhile, $\mathrm{Ag}_{2} \mathrm{~S}$ NPs have antimicrobial, bioimaging, and diagnostic ability. CdS NPs show antimicrobial and anticancer activities [17]. To date, no USFDA approved sulfide NPs are available in the market. Nevertheless, hollow mesoporous copper sulfide NPs are in the preclinical phase and are promising towards advancing further to clinical practice. They are tried for the delivery of doxorubicin (DOX) using either $\mathrm{FeO}$ or hyaluronic acid [22].

\section{Bimetallic NPs}

NP developed from two metals forms a bimetallic NP (e.g., FePt, FeCo, FeNi, CuNi). The excellent magnetic property of $\mathrm{FeCo} \mathrm{NPs}$ is suitable for magnetic resonance imaging. FeCo NPs are susceptible to oxidation, hence, their biocompatibility is ensured by giving suitable coating [23]. On the other hand, FePt NPs are stable towards oxidation and have good biocompatibility with superparamagnetic properties. Surface functionalization of FePt NPs further enhanced the stability and biocompatibility. They are investigated in the field of magnetic resonance imaging, magnetic hyperthermia, and drug delivery applications [24].
The magnetic properties of FeNi NPs made them suitable for magnetic resonance imaging contrast agents. CuNi NPs are stable, biocompatible with good curies temperature, and utilized in magnetic hyperthermia [25]. The bimetallic NPs are still under preclinical trials and, therefore, approved products are not available for clinical use. Interestingly, AuPt bimetallic NPs have been predicted for their success in therapeutic applications over monometallic NPs [26]. Very recently, AuRu NPs have been found effective against multi-drug resistant Gram-negative bacteria [27].

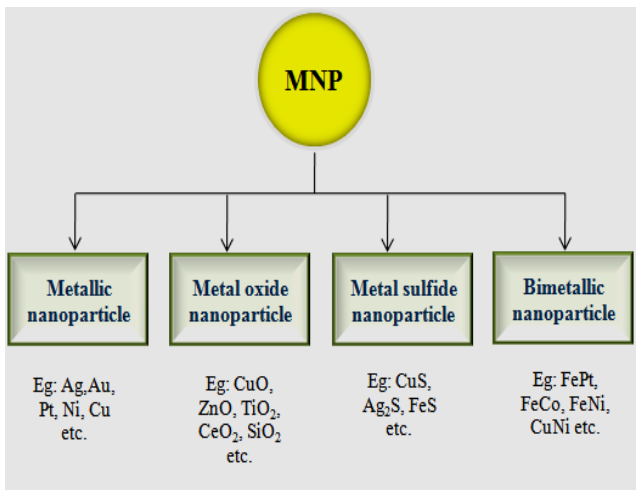

Figure 1. Types of metal nanoparticles (MNP)

\section{PROPERTIES OF MNPS}

The interesting properties of MNPs that contribute to various applications arise from their large surface energy, surface atom, spatial confinements, and structural perfections. For the application of MNPs for therapeutic purposes, the properties of MNPs under physiological conditions are very important. Their stability and behavior under biological fluids are entirely different from in vitro conditions. Ross et al. characterized different MNPs ( $\mathrm{Au}, \mathrm{Ag}, \mathrm{Fe}_{2} \mathrm{O}_{3}$, $\mathrm{TiO}_{2}$, and $\mathrm{ZnO}$ ) under the conditions of physiological fluids and water. The properties differed with the type of MNP, size, and concentration; $\mathrm{Au}$ and $\mathrm{Ag}$ NPs are found to be more stable than others [28].

\section{Optical properties}

The optical properties of MNPs differ from their bulk material. It depends on the type, size, and shape of the MNP, and the media. The optical properties arise due to the surface interaction of MNP with electromagnetic radiation. MNPs composed of noble metals show characteristic localized surface plasma resonance (LSPR), which is not seen in bulk metal. The color of the MNPs varies with the size of the 
particle. AuNPs appear in intense red at a particle size of less than $100 \mathrm{~nm}$, while a yellow color appears at a larger size $[29,30]$.

\section{Magnetic properties}

The magnetic properties of MNP have been investigated in various fields such as imaging, catalysis, biomedicine, etc. The distribution of electrons in MNP is not in an even manner. This is responsible for the magnetic properties of MNPs. As the particle size of the MNPs decreases to less than $20 \mathrm{~nm}$, the magnetic property prevails to the maximum. As the particle size decreases and reaches a particular level, the MNPs exhibits superparamagnetic behavior (e.g., PtNPs at a diameter less than $3.8 \mathrm{~nm}$ ) [31].

\section{Thermal properties}

MNPs are found to be having a lower melting point than the bulk metal. This arises due to the fact that the reduction in particle size results in large surface energy that lowers the transition temperature. On the other hand, the thermal conductivity of the metal is increased on conversion to nano-form; since heat transfer takes place at particle surface $[30,32]$.

\section{Mechanical properties}

The mechanical properties of a material change on conversion to the nano-size range. There is an improvement in mechanical properties when compared to bulk form. This enhancement arises due to the structural perfection attained by the nanomaterial [33]. The mechanical properties of an MNP depend on several factors such as type of the material, production process, grain size, and grain boundary structure. MNPs have higher fracture toughness and fracture strength than other nanomaterials. The addition of MNPs enhances the mechanical properties of materials [34].

\section{SYNTHESIS OF MNPs}

The methods of preparation of MNP are similar to those for other NPs. Depending upon the basic principle involved in the synthesis; the method of preparation can be classified into two categories: topdown and bottom-up methods. The main difference encountered in these methods is the starting material employed in the synthesis.

\section{Top-down method}

This method involves the utilization of large-sized material, which is effectively reduced to the nanosize range using different methods such as mechanical milling (ball milling and mechanochemical methods), laser ablation, and spluttering.

Mechanical milling involves the use of a high energy milling equipment in which the material is placed for size reduction. In the case of ball milling, the bulk material is placed in a mill containing high energy rotating balls. After the process, the surface of the particles gets modified. In the mechanochemical method, different chemicals for NP formation are mixed mechanically and the reactions occur at the interface between the reagents. The laser ablation method involves the use of laser irradiation for size reduction. The properties of NPs thus formed depend on the factors like exposure time, the energy of laser irradiation, surrounding media, etc.

The spluttering method is performed in an evacuated vacuum chamber, in which the metal to be converted is maintained at a high voltage. Inert gas is introduced into the chamber, which interacts with metal, resulting in the ionization of inert gas. The NPs are formed by the interaction of gas ions with metal targets (Table 1) [35,36].

\section{Bottom-up method}

This involves the utilization of small materials (atoms, molecules, etc.), which are effectively converted to nano-size range using different methods such as solid-state methods (physical vapor deposition and chemical vapor deposition), liquidstate synthesis methods (sol-gel, chemical reduction, and hydrothermal methods), gas-phase methods (solvothermal method, spray pyrolysis, laser ablation, and flame pyrolysis), biological methods (bacteria, fungus, yeast and algae, and plant extract), and other methods (electrodeposition process, microwave technique, supercritical fluid precipitation process, and ultrasound techniques).

In physical vapor deposition, NPs are formed by the vaporization of material, followed by condensation on a substrate. The material may condense either as a film or as NPs. While in chemical vapor deposition, the vaporized material 
then undergoes chemical reactions and get deposited on a substrate as a thin film.

The sol-gel method involves the use of colloidal metal (sol) and a matrix-forming liquid phase (gel) mixed together, which on the addition of suitable catalyst undergo various processes such as hydrolysis and condensation, followed by particle growth and their agglomeration. Tetramethoxysilane and tetraethoxysilane are commonly used for gel formation. The chemical reduction method utilizes a reducing agent for the effective reduction of metal ion salt that results in MNP formation [36].

In the hydrothermal method, the solid substrate interacts with vapors of an aqueous solution. The reaction can be carried at different temperature and pressure conditions based on the properties of reactants and product required [37].

Solvothermal reactions occur at high temperature and pressure in the presence of a solvent, usually non-aqueous. The use of microwave in the solvothermal method enhances the crystal formation. In spray pyrolysis, the metal substrate is sprayed into the reactor chamber, which is then collected as MNPs by the precipitator. On the other hand, laser pyrolysis employs laser energy, absorbed by a metal substrate that causes induction of nucleation reaction. Flame pyrolysis is carried out with a flame, into which metal precursor in liquid form is sprayed for MNP generation.
Chemical and physical methods of MNPs synthesis involve several environmental and health hazards; so, several green synthetic methods are developed for generating MNPs with environmentally safer byproducts [38]. The current trend is to develop MNPs using different biological agents. The biological method, also a green synthesis method, is an interesting approach for MNP synthesis. Here different biological agents such as microbes (bacteria, fungus, yeast, and algae), plants, and plant extracts are used for MNP synthesis. The method is valuable since it is environmentally safer, cheap, and no need for high temperature, pressure, energy, or hazardous chemicals [29]. The green method also has the advantage of purity and reproducibility [30,39-42].

The electrochemical deposition method employs an electrochemical cell containing metal salt in the electrolyte, an anode, a cathode, and a reference electrode $(\mathrm{Ag} \backslash \mathrm{AgCl})$. MNPs formed are deposited on the cathode. Supercritical fluid technology involves the use of supercritical fluid that expands in a reactor at high pressure and interacts with a solution of a metal precursor, forming MNPs. Ultrasound technique is performed with the use of an ultrasound that atomizes the metal precursor into the reactor and the MNPs formed are collected by the collecting unit of the reactor [36].

Table 1. Different methods of metal nanoparticles (MNPs) synthesis and their application

\begin{tabular}{|c|c|c|c|c|}
\hline MNP & Synthesis method & Size (nm) & Application & Reference \\
\hline Ag & $\begin{array}{l}\text { Biological method using } \\
\text { Bacillus sp. KFU36 }\end{array}$ & $5-15$ & Anticancer activity & [43] \\
\hline $\mathrm{ZnO}$ & Solochemical process & $80.1-90$ & Antibacterial activity & {$[44]$} \\
\hline Ag & $\begin{array}{l}\text { Green synthesis using Nepeta } \\
\text { deflersiana plant extract }\end{array}$ & 33 & Anticancer activity & {$[32]$} \\
\hline Au & $\begin{array}{l}\text { Green synthesis using Taxus } \\
\text { baccata extracts }\end{array}$ & $<20$ & Anticancer activity & {$[45]$} \\
\hline $\mathrm{CuO}$ & $\begin{array}{l}\text { Green synthesis using black } \\
\text { bean extract }\end{array}$ & $\sim 26.6$ & Anticancer activity & [46] \\
\hline $\mathrm{CuO}$ & Sol-gel method & 70 & Drug delivery & {$[47]$} \\
\hline $\mathrm{ZnO}$ & Liquid state synthesis & 40 & $\begin{array}{l}\text { Antibacterial and } \\
\text { anticancer activity }\end{array}$ & {$[48]$} \\
\hline
\end{tabular}




\begin{tabular}{|c|c|c|c|c|}
\hline Au & Rapid stirring & 95 & Gene delivery & [49] \\
\hline $\mathrm{Ye}_{2} \mathrm{O}_{3}$ & Magnetic stirring & 15 & Tissue engineering & [33] \\
\hline Au & Chemical reduction & $27 \pm 3$ & Tissue engineering & [50] \\
\hline Au & Chemical reduction & 20 & Tissue engineering & [51] \\
\hline Ag & $\begin{array}{l}\text { Green synthesis using } \\
\text { Curcuma longa tuber powder }\end{array}$ & 102 & Bioimaging & [52] \\
\hline $\mathbf{C u}$ & $\begin{array}{l}\text { Green synthesis using } \\
\text { Curcuma longa tuber powder }\end{array}$ & 190 & Bioimaging & {$[52]$} \\
\hline Pd & Chemical reduction & $2 \pm 0.8$ & Bioimaging & {$[53]$} \\
\hline $\mathbf{C u}$ & Chemical reduction & $0.5 \pm 1.5$ & Bioimaging & [54] \\
\hline
\end{tabular}

\section{SAFETY PROFILE}

MNP has a wide range of applications in various fields. For their applications in biomedicine, their toxicity profile in the human body must be considered. Unfortunately, the unwanted adverse effects also arise from their characteristic physicochemical properties [14,55-57]. The route of administration of NP is important in determining the extent of toxicity and tissues involved [58].

Surface modification of MNPs helps in lowering the toxicity and enhances the biocompatibility [59]. Polyacrylate coated $\mathrm{TiO}_{2} \mathrm{NPs}$ were found to be less toxic than uncoated $\mathrm{TiO}_{2} \mathrm{NPs}$. The cytotoxicity studies in Chinese hamster lung fibroblast (V79) cells ensured that $\mathrm{TiO}_{2} \mathrm{NPs}$ are safer at a lower concentration $(1 \mathrm{mg} / \mathrm{L})$. A significant decrease in cell viability was observed at $10 \mathrm{mg} / \mathrm{L}$ and higher concentrations. Coated $\mathrm{TiO}_{2} \mathrm{NPs}$ remain unaffected at 1 and $10 \mathrm{mg} / \mathrm{L}$ and the cell viability reduced to $85 \%$ at $100 \mathrm{mg} / \mathrm{L} \mathrm{[60].}$

Being liver the major detoxification center of the human body, chances of accumulation of MNP in it is greater than other organs and tissues. Hepatic cell death occurs due to oxidative stress build-up due to MNP accumulation that impairs the antioxidant mechanism of the liver [56].

The toxicity of MNPs increases with the decrease in size $[9,57,61]$. AuNPs with smaller sizes $(1-2 \mathrm{~nm})$ are found to be more toxic than the larger ones $(15 \mathrm{~nm})$. The cytotoxicity s mainly dependent on the size of NPs rather than the ligand used for functionalization and the cell type involved [62]. The cellular uptake of AuNPs can be augmented by decreasing the particle size. On the other hand, the presence of serum reduces the toxicity of MNP by reducing the cellular interactions. The serum contains proteins that can interfere with the cellular uptake of MNPs [63]. While considering the AuNPs of different shapes; spherical and prismatic AuNPs coated with CTAB are potentially toxic than rod and cube-shaped corresponding particles [64].

The cytotoxic effects of AgNPs start appearing at a dose of $1 \mathrm{mg} / \mathrm{L}$. At this dose, morphological changes appeared to HepG2 human hepatoma cells along with micronuclei formation and alteration in gene expression [65]. Similarly, in human mesenchymal stem cells (hMSCs), cytotoxicity appeared at $10 \mu \mathrm{g} / \mathrm{mL}$ and at subtoxic concentration $(0.1 \mu \mathrm{g} / \mathrm{mL})$, activation of hMSCs occurred [66]. Among the two colloidal silver NPs, those stabilized with ammonia (SNA) show greater toxicity than with PVP (SNP). SNA is cytotoxic at $15 \mu \mathrm{g} / \mathrm{mL}$, while $\mathrm{SNP}$ at $25 \mu \mathrm{g} / \mathrm{mL}$ [67].

The results of MTT assay among the different metal oxide NPs showed that $\mathrm{ZnO}$ exhibited greater toxicity [68-70]. On studying the effect of ZnO NPs on human lung epithelial cells (L-132), a linear decrease in cell viability is observed with increasing the concentration of $\mathrm{ZnO}$. The toxicity arises due to oxidative stress induced by the production of reactive oxygen species (ROS) causing cell shrinkage, DNA damage, and apoptosis [71]. Ahmad et al. studied the genotoxic effects of $\mathrm{CuO}$ NPs in human pulmonary epithelial cells (A549). The cytotoxicity arises from oxidative stress characterized by depletion of reduced glutathione and enhanced lipid peroxidation. Upregulation of expression of Hsp70 (Heat shock protein 70), p53 (cell cycle checkpoint protein), and Rad51 and MSH2 (DNA damage repair proteins) indicates the genotoxic potential of CuO NPs [72].

A study compared the effect of different metal oxide NPs $\left(\mathrm{TiO}_{2}, \mathrm{Al}_{2} \mathrm{O}_{3}, \mathrm{ZnO}\right.$, and $\left.\mathrm{CrO}_{3}\right)$ on cell mitochondria. After $24 \mathrm{~h}$ exposure of NPs on mouse neuroblastoma, CCL-131, and ATCC cells, ZnO 
exhibited more cytotoxic effects than others and the mitochondrial function get reduced to more than $80 \%$ at $100 \mu \mathrm{g} / \mathrm{mL}$. $\mathrm{TiO}_{2}$ NPs have no effects up to $200 \mu \mathrm{g} / \mathrm{mL}$ concentration. $\mathrm{Al}_{2} \mathrm{O}_{3}$ at $100 \mu \mathrm{g} / \mathrm{mL}$, caused a $15 \%$ decrease in mitochondrial function. Meanwhile, $\mathrm{CrO}_{3}$ was found safe even at $200 \mu \mathrm{g} / \mathrm{mL}$ concentration [70].

Even though MNPs have toxic effects on the biological system, they have a concentration range in which they are safer for use in biomedicine. Hence the selection of a suitable concentration range avoids the problem of toxicity issues.

\section{BIOMEDICAL APPLICATIONS}

\section{Antimicrobial activity}

The extensive use of various antimicrobial agents in treating various disease conditions leads to the development of antimicrobial resistance [73]. At present, the development of an effective antimicrobial agent is necessary for solving the problem of antimicrobial resistance.

MNPs have strong antimicrobial activity with targeted action (owing to their nano-size). MNPs mainly interact with microbial cell membranes causing their disruption and decrease microbial enzyme activity, affecting the metabolic pathways [74]. They can also generate ROS, thus damaging the genetic material [41,75-77].

AgNPs synthesized from the dark and white seeds of Salvia hispanica L. showed antibacterial activity against E. coli and S. aureus. The activity of AgNPs from dark seeds was higher than the white one [8]. Thermosensitive AgNPs generated from PNIPAM-co-MQ copolymer have a temperaturedependent antibacterial activity against both Gramnegative and Gram-positive bacteria through cell destruction and ROS generation [78]. AgNPs synthesized in presence of chitosan exhibited both antibacterial and antifungal activity. The observed diameter of zone of inhibition for Bacillus sp., Staphylococcus, and Aspergillus niger was 15, 13, and $15 \mathrm{~mm}$, respectively, with a higher action for Pseudomonas sp. $(24 \mathrm{~mm})$. The chitosan used in the synthesis of AgNPs acts as a protective agent and enhances the antibacterial activity [79].

AgNPs in the size range of $15-20 \mathrm{~nm}$ produced from the aqueous extract of apple interact with bacterial cell membrane causing their damage through the free radical generation and deactivated the bacterial enzymes resulting in their action against Gram-positive and Gram-negative bacteria [80]. AgNPs biologically synthesized using Sphingobium sp. MAH-11 have activity against multidrugresistant strains of $\mathrm{S}$. aureus, E. coli, and $\mathrm{P}$. aeruginosa. The antimicrobial action arises from the interruption of the reproductive mechanism through cell damage that resulted in bacterial cell death [81].

The nanocomposites developed from two MNPs broadens their spectrum of antimicrobial activity. $\mathrm{Ag}-\mathrm{Cu}$ nanocomposites produced in presence of Olax scandens leaf extract (which act as a reducing and stabilizing agent) extend their

Table 2. Antimicrobial activity of metal nanoparticles (MNPs)

\begin{tabular}{lllll}
\hline MNP & Size (nm) & Susceptible organism & Mechanism of action & Reference \\
\hline $\mathbf{A g}$ & 7 & E. coli and S. aureus & $\begin{array}{l}\text { Inhibition of cell } \\
\text { transduction } \\
\text { Cell membrane destruction, } \\
\text { internalization, and ROS } \\
\text { generation }\end{array}$ & {$[78]$} \\
$\mathbf{A g}$ & $1.5-4$ & E. coli and S. aureus & $\begin{array}{l}\text { Binding to cell } \\
\text { membrane and } \\
\text { alteration of cell } \\
\text { permeability }\end{array}$ & [79] \\
& $10-6$ & $\begin{array}{l}\text { S. aureus, Bacillus sp., E. coli, } \\
\text { Proteus sp., Pseudomonas sp., } \\
\text { Serratia sp., Klebsiella sp., } \\
\text { Aspergillus niger, Aspergillus } \\
\text { flavus, Aspergillus fumigatus, } \\
\text { and Candida albicans }\end{array}$ & & \\
& & &
\end{tabular}

Table 2 continues... 


\begin{tabular}{|c|c|c|c|c|}
\hline Ag & $10-20$ & E. coli and S. aureus & $\begin{array}{l}\text { Adsorption on cell } \\
\text { surface, ROS } \\
\text { generation and damage } \\
\text { to surface integrity }\end{array}$ & {$[80]$} \\
\hline Ag & $7-22$ & $\begin{array}{l}\text { E. coli and } \mathrm{S} \text {. aureus and } \mathrm{P} \text {. } \\
\text { aeruginosa, }\end{array}$ & $\begin{array}{l}\text { Damaged Membrane } \\
\text { integrity, interruption } \\
\text { of reproductive } \\
\text { mechanism }\end{array}$ & [81] \\
\hline $\mathrm{Ag}-\mathrm{Cu}$ & $10-20$ & $\begin{array}{l}\text { E. coli and S. aureus, K. } \\
\text { pneumoniae, P. aeruginosa, and } \\
\text { C. albicans }\end{array}$ & $\begin{array}{l}\text { ROS generation, cell } \\
\text { membrane damage, } \\
\text { denaturation of } \\
\text { enzymes and protein, } \\
\text { DNA damage }\end{array}$ & {$[82]$} \\
\hline $\mathrm{ZnO}$ & $80.1-90$ & $\begin{array}{l}\text { S. aureus, Salmonella } \\
\text { Typhimurium, Bacillus cereus } \\
\text { and } P \text {. aeruginosa }\end{array}$ & $\begin{array}{l}\text { ROS generation, } \\
\text { oxidative stress, } \\
\text { membrane damage }\end{array}$ & [44] \\
\hline CdO & $40-60$ & $\begin{array}{l}\text { S. aureus, Shigella dysenteriae } \\
\text { and P. aeruginosa }\end{array}$ & ROS generation & {$[83]$} \\
\hline Au & $20 \pm 5$ & $\begin{array}{l}\text { Streptococcus bovis, S. } \\
\text { epidermidis, Enterobacter } \\
\text { aerogenes, P. aeruginosa, and } \\
\text { Y. pestis }\end{array}$ & $\begin{array}{l}\text { Cell membrane } \\
\text { disruption and leakage } \\
\text { of cytoplasmic } \\
\text { contents }\end{array}$ & [84] \\
\hline Ag & $3.30-17.97$ & E. coli and Bacillus cereus & Cell membrane injury & {$[46]$} \\
\hline
\end{tabular}

spectrum of activity towards drug-resistant microbes also. The enhanced antimicrobial activity arises from the combined effect of individual MNPs. The drugresistant strains such as P. aeruginosa (ampicillinresistant) K. pneumoniae (ampicillin, kanamycin, and gentamycin resistant) are also susceptible to the activity of $\mathrm{Ag}-\mathrm{Cu}$ nanocomposites [81].

From the antibacterial study of $\mathrm{ZnO}$ NPs prepared via a solo chemical process, the Gramnegative organisms (S. aureus, Salmonella typhimurium, and P. aeruginosa) were found to be susceptible. On the other hand, the Gram-positive organism (Bacillus cereus) was unaffected by the action of NPs. The minimum inhibitory concentration (MIC) was found to be $0.05 \mathrm{mg} / \mathrm{mL}$ and the minimum bactericidal concentration (MBC) was $0.5 \mathrm{mg} / \mathrm{mL}$ for both $\mathrm{S}$. aureus and Salmonella typhimurium [44].

On examining the bactericidal action of $\mathrm{CdO}$ NPs obtained from fungus Penicillium oxalicum, Gram-negative organism was found to be more affected than Gram-positive organism. The antibacterial activity arises due to the destruction of cell membranes and the depression of metabolic enzymes [83].
Conjugation of antibiotic drug kanamycin to gold NPs enhanced the spectrum of activity, and the developed AuNPs showed activity against kanamycin-resistant organisms also. Conjugation resulted in a significant reduction in MIC values for all tested strains, which may be due to the fact that AuNPs themselves show antimicrobial activity [84]. Interestingly, bacterial biomass itself can be used for MNPs synthesis. $\mathrm{AgNO}_{3}$ in the presence of cyanobacterium (Oscillatoria limnetica) biomass gives rise to AgNPs in the size range of 3.30-17.97 $\mathrm{nm}$. Here, the presence of different groups (free amino groups, sulfur-containing amino acid derivatives, and sulfur or phosphorus groups) further stabilized the AgNPs [46].

\section{Anticancer activity}

Different treatment approaches used for managing life-threatening cancer includes surgery, chemotherapy, and radiation therapy [85]. These methods are effective in cancer treatment but are associated with many disadvantages. The relevance of nanotechnology in cancer therapy is from the early detection and analysis of tumors [86]. The studies on MNPs for cancer therapy are related to exploring the advantage of nanotechnology. Metals have inherent cytotoxicity and conversion to nano-form results in a reduction in particle size with a large surface-volume 
ratio, which facilitates the interaction with tumor cells and a large surface area allows the functionalization with targeting agents for selective therapy $[46,87]$.

AgNPs synthesized from Bacillus sp. KFU36, a marine strain, exhibited significant anticancer activity in MTT and wound healing assays. The studied AgNPs were in the size range of 5-15 nm; induced morphological changes and decreased the viability of MCF-7 cells with the increase in AgNPs concentration [43]. Loufty et al. evaluated both AuNPs and AgNPs for anticancer activity. Both the MNPs show anticancer activity in a dose-dependent manner; with an $\mathrm{IC}_{50}$ value of $6.28 \mu \mathrm{M}$ for AgNPs (5$10 \mathrm{~nm})$ and $14.48 \mu \mathrm{M}$ for AuNPs (13-15 nm). These antitumor activities arise due to the inhibitory effect on cell division phase and apoptosis [88]. AgNPs prepared from aqueous extract of the plant Nepeta deflersiana showed a concentration-dependent cytotoxic action in cervical cancer (HeLA) cells. In the MTT assay, the cell viability decreased to $86 \%$ and $29 \%$ with the AgNP concentration of 2 and 5 $\mu \mathrm{g} / \mathrm{mL}$, respectively. Meanwhile, in NRU assay, the cell viability decreased to $87 \%$ and $43 \%$ with the AgNPs concentration of 2 and $5 \mu \mathrm{g} / \mathrm{mL}$, respectively. Morphological changes in HeLa cells (alteration in shape, cell shrinkage, etc.) were also observed. The cytotoxicity arises from oxidative stress build in the cells due to ROS generation and decreased level of glutathione and increase in lipid peroxidase level [32].

A comparative anticancer study was done with two different MNPs ( $\mathrm{Au}$ and $\mathrm{ZnO}$ NPs). Among them, $\mathrm{ZnO}$ showed higher anticancer activity in HT29 cancer cells. AuNPs exhibited anticancer activity in a concentration-dependent manner by the inhibition of the angiogenesis process, and the $\mathrm{IC}_{50}$ value was found to be $48 \mu \mathrm{g} / \mathrm{mL}$. $\mathrm{ZnO}$-induced cytotoxic action arises due to the ROS production and apoptosis. It also exhibited anticancer activity in a concentration-dependent manner with an $\mathrm{IC}_{50}$ value of $17.12 \mu \mathrm{g} / \mathrm{mL}$. Conjugation of $\mathrm{ZnO}$ NPs with hydrophobic peptide further enhanced the cytotoxicity towards HT29 cancer cells and hence contributes to targeted cancer therapy [87].

Stable and biogenic AuNPs were synthesized in presence of aqueous and ethanolic extracts of Taxus baccata and $\mathrm{HAuCl}_{4}$ solution. The size of the obtained encapsulated AuNPs was less than $20 \mathrm{~nm}$.
The results of the MTT assay in three cancer cell lines (MCF-7, Caov-4, and HeLa) showed that the AuNPs synthesized in the ethanolic extract is more cytotoxic than aqueous extract. The cell mortality rate after $72 \mathrm{~h}$ exposure was 80,92 , and $98 \%$ for Caov-4, MCF-7, and HeLa cancer cells, respectively at a concentration of $20 \mu \mathrm{g} / \mathrm{mL}$ (Figure 2) [39].

Being $\mathrm{Cu}$ a heavy metal with cellular toxicity can be applied for cancer therapy. CuO NPs ( 26.6 $\mathrm{nm})$ produced in presence of the aqueous extract of Phaseolus vulgaris induced morphological changes, apoptosis, and necrosis in HeLa cells. Their toxic effects on normal cells can be reduced by targeted therapy [46].

\section{Drug and gene delivery}

The main objective of drug therapy with nanocarriers is to overcome the limitations of conventional therapy [89]. MNPs can be employed as a carrier for site-specific delivery of drugs. The anticancer efficacy of cytotoxic drugs can be enhanced by combining with MNPs. 5FU can be effectively targeted to tumor cells by designing a nanocomposite of reduced graphene oxide-AuNPs. The nanocomposite exhibited higher inhibition towards MC7 cancer cells at 5\% concentration. The enhanced apoptotic action is due to the generation of ROS and antioxidant action. The nanocomposite allows easy penetration of the drug into tumor cells, providing the way for 5FU action [90]. A sustained drug delivery carrier was developed by ingraining ZnO NPs in histidine conjugated chitosan hydrogel, cross-linked with dialdehyde cellulose. The obtained carrier loaded with naringenin, quercetin, and curcumin, and the antimicrobial and anticancer activities were studied. The presence of ZnNPs enhanced the drug loading, release, and anticancer activity. The anticancer study was carried out with A431 human skin carcinoma cells and the results showed that the cytotoxicity increased to 15 fold (quercetin and naringenin), 30 fold (curcumin) than that of the initial drug. The results of the antimicrobial study showed that there is a significant increase in the diameter of the zone of inhibition when the drug was incorporated into the developed carrier [91].

MNPs can be used for formulating drugcontaining metallic nanocapsules that allow the retention of drugs at the tumor site without any leakage in other unwanted areas. These MNPs provide an impermeable shell protecting the highly 


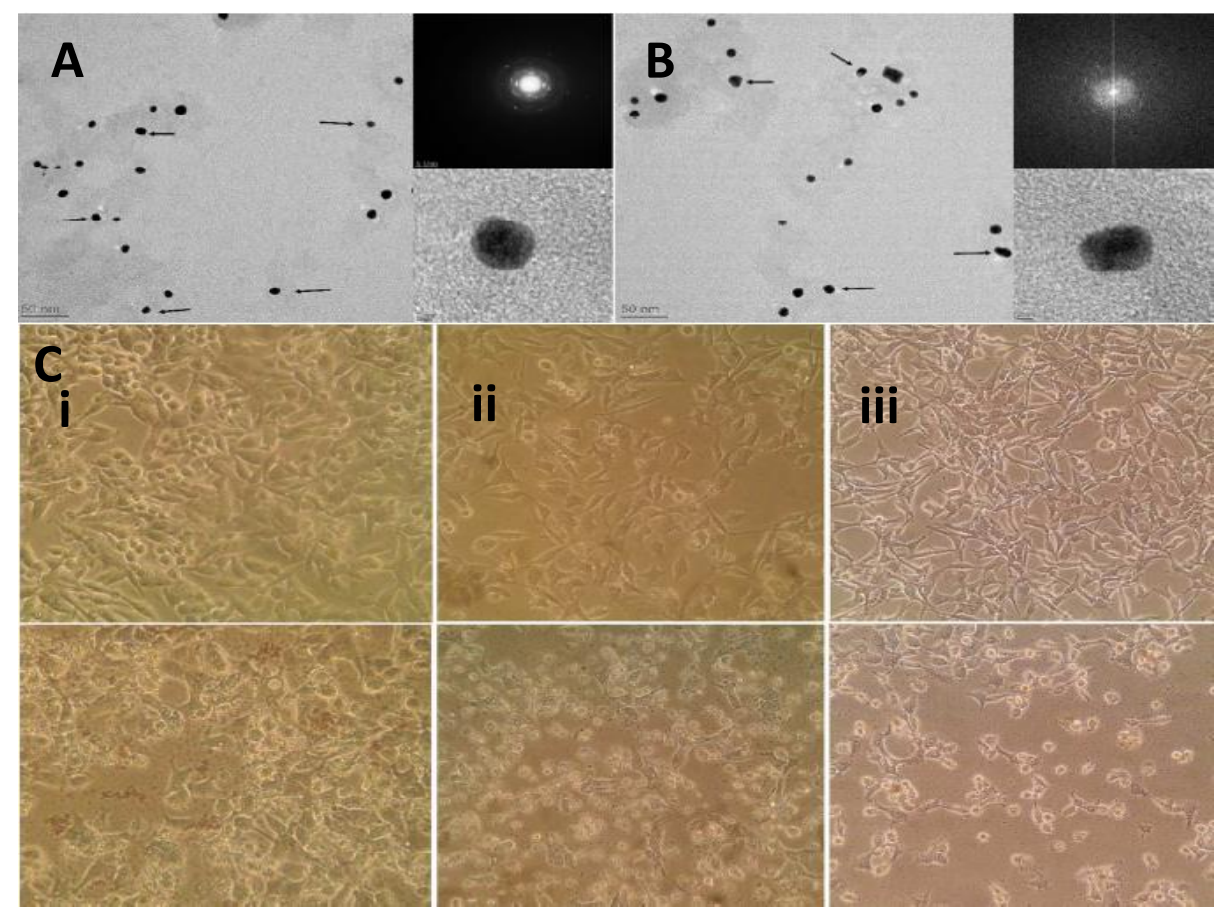

Figure 2. Transmission electron microscopy images of AuNPs synthesized using (A) ethanolic and (B) aqueous extracts of T. baccata. (C) Morphological changes of (i) Caov-4), (ii) HeLa, and (iii) MCF-7 cancer cells after treatment with gold nanoparticles for $48 \mathrm{~h}$. Control is shown at the top. Reproduced by permission from [39] () 2016 The Royal Society of Chemistry

potent drugs in the circulation for safer delivery to the required site. A Pickering emulsion was formulated in which PtNPs were adsorbed at the emulsion interface forms a metallic core, which protected the highly potent anticancer drug paclitaxel from its leaching in blood circulation. The drug release at the target site can be achieved by ultrasound [92].

Interestingly, non-iron MNPs can also be used to improve the stability of iron oxide NPs. Coating iron oxide NP with $\mathrm{Au}$ or Ag NPs generates a magnetic core with good adsorption property. Drugs like cisplatin and mercaptopurine can be adsorbed on the surface and the drug targeting can be achieved by magnetic hyperthermia since the magnetic moment of the $\mathrm{Fe}$ atom remains even after the metallic coating. After targeting the drug at the tumor site, drug release occurs due to the low $\mathrm{pH}$ of the cancer cells. Among the two coatings, Au coating enhanced the adsorption energy, while the drug mercaptopurine showed higher adsorption [93].
Further, MNPs can be conjugated with polymers for developing drug delivery carriers. $\mathrm{CuO}$ NPs on conjugation with hyperbranched polyglycerol give rise to a drug delivery carrier with $\mathrm{CuO} \mathrm{NP}$ core and a polymer shell. Loading the drug tetracycline into this delivery carrier results in a controlled drug delivery system and guarantee its application in chronic infection. The antibacterial activity of the obtained carrier was remarkably higher than the drug alone. The zone of inhibition was found to be increased to $20 \mathrm{~mm}$, while for the drug alone is $16 \mathrm{~mm}$. The results of the MTT assay revealed that the obtained carrier has no cytotoxicity towards MCF-7 cells and L-929 mouse fibroblast cells [47].

The anticancer and antimicrobial activities of drugs can be enhanced by MNPs. Curcumin on conjugation with $\mathrm{ZnO}$ NP coated with chitosan, a synergistic effect was observed. The obtained conjugate has a particle size of $40 \mathrm{~nm}$ with remarkable apoptotic effects on MDA-MB-231 breast cancer cells with no effects on normal cells 
(HEK293). The antimicrobial study revealed that there is a 25-50 fold decrease in MIC value and 1040 fold decrease in $\mathrm{MBC}$ value against $\mathrm{S}$. aureus and E. coli. Other than this, the conjugate exhibited a $\mathrm{pH}-$ responsive drug release owing to the use of $\mathrm{N}$ succinyl chitosan, allowing the drug release at the target site. The increased therapeutic activity arises from the combined use of $\mathrm{ZnNP}$, chitosan, and curcumin [48].

Investigations are also carried out with MNPs for gene delivery application. This is mainly advantageous in the case of slowly proliferating cells such as stem cells that are difficult for transcription by non-viral gene delivery vectors. Cationic MNPs on conjugation with TAT peptide forms an efficient gene delivery vector for conveying genes to stem cells. Cationic MNPs generated using PEI in the preparation of Au or Ag NPs. Au@PEI or Ag@PEINPs so formed are further conjugated with TAT peptide and then condensed with DNA to deliver genes to stem cells. The transfection efficiency of green fluorescent protein plasmid DNA was calculated from fluorescence intensity using flow cytometry, and the result shows that the designed vector has higher transfection ability when compared to PEI-DNA complexes. The vector containing two types of MNPs shows similarity in transfection due to the similarity in DNA binding, size, zeta potential, etc. of the vectors. The presence of MNP in the vector effectively reduced the cytotoxicity of the cationic polymer and about $90 \%$ of cell viability was observed [11]. AuNPs synthesized in the presence of starch-PEI conjugate form a non-viral gene delivery carrier for cancer therapy. In the conjugate, starch acts as a stabilizer and PEI acts as a reducing agent for AuNP synthesis. The transfection efficiency of the carrier is further enhanced using amino acids Larginine or L-histidine during the conjugation of starch with PEI. The use of this modified conjugate in MNP synthesis results in an increase in amine density of the carrier, which facilitates the endosomal escape necessary for gene transfection [49].

\section{Tissue engineering}

The research in tissue engineering are becoming more important due to the requirement of tissues for the purpose of organ failure, and for other diseases in which tissue replacement is necessary. Problems such as deficits in matching donors, immunological issues, financial expenses, etc. in organ transplantation made tissue engineering as a favorable alternative.

Tissue engineering involves the use of modified tissues, called tissue scaffold, for the purpose of tissue repair or replacement. The properties and functionalities of the scaffold are important in tissue engineering $[94,95]$. The scaffold properties can be augmented using NPs. The presence of NPs amplifies the mechanical and biological properties in tissue engineering [45]. Among the NPs, metallic NP, especially AuNP attracted scientific interest on the account of their fascinating properties. On incorporation of AuNPs, the functionality of the scaffold is improved [96].

The antimicrobial potential of AgNPs can be used for skin tissue engineering for treating severe burns. A nanofibrous mat prepared from tasar (Antheraea mylitta) coated with AgNPs was proposed for pursuing the antimicrobial activity. The antimicrobial potential is particularly important for skin tissue scaffolds for burns since the risk of microbial growth is higher in a burn, which further worsens the condition. AgNPs incorporation to nanofibrous mat provides antimicrobial activity towards Gram-negative and Gram-positive organisms. The diameter of the zone of inhibition was 10 and $14 \mathrm{~mm}$ for $\mathrm{S}$. aureus and E. coli, respectively. On the other hand, it was 8 and $10 \mathrm{~mm}$ for $\mathrm{P}$. aeruginosa and $\mathrm{S}$. epidermidis, respectively.

Other than this, the presence of AgNPs enhanced the mechanical strength, water absorption power, and porosity of the nanofibrous mat. The results of the MTT assay in L929 fibroblast cells ensured the cell proliferation ability of the developed nanofibrous mat [97]. Similarly, the presence of $\mathrm{Y}_{2} \mathrm{O}_{3}$ (yttrium oxide) NPs augmented the proliferation and angiogenesis functionality of the polycaprolactone (PCL) scaffold. The concentration of $\mathrm{Y}_{2} \mathrm{O}_{3}$ in the scaffold was important and the maximum activity was found at $1 \% \mathrm{w} / \mathrm{w}$. A significant increase in the diameter of blood vessels observed during chick chorioallantoic membrane assay when compared to the scaffold without $\mathrm{Y}_{2} \mathrm{O}_{3}$ NPs. There is an increase in the expression of growth factor gene VEGF mRNA and inflammatory genes COX-2 (cycloxygenase-2) and TNF- $\alpha$ (tumor necrosis factor- $\alpha$ ). After the fourth week of the study, inflammatory genes got downregulated [33]. 
Polymeric networks called hydrogels in combination with metal NPs forms superstructures with excellent properties that are appropriate for tissue engineering. Hydrogels have good biocompatibility, water holding capacity, drug retaining power, sufficient porosity, and biodegradability that are beneficial for new tissue and blood vessel formation [98].

When hydroxyl ethyl cellulose (HEC) is used for scaffold preparation in presence of $\mathrm{AgNO}_{3}$, HECAgNP tissue scaffold is formed with good biocompatibility and porosity. As the concentration of $\mathrm{AgNO}_{3}$ solution increases, the cell proliferation rate also increases [99]. Gelatin hydrogel loaded with AgNPs reinforces bone regeneration. When the cell proliferation rate was determined with CCK assay using human adipose-derived stem cells (ADSCs), it was found to be increasing with the amount of AuNPs and reached to $28 \%$ after $72 \mathrm{~h}$ of incubation. An increase in alkaline phosphate (ALP) activity with the increase in AuNPs confirmed the osteogenic differentiation of ADSCs in vitro. Under in vivo condition, the hydrogels applied at bone defect site effectively enhanced the regenerated bone volume after 4-8 weeks (Figure 3) [50]. AgNPs loaded nanofibres (114.86 - $126.90 \mathrm{~nm})$ synthesized from carboxymethyl cellulose (CMC) and polyvinyl alcohol (PVA) manifests good biocompatibility and cell proliferation. Studies on human fibroblast $(\mathrm{hFB})$ cells have shown that higher proliferation rate is observed at a concentration of $2 \%$ of $\mathrm{AgNO}_{3}$ solution [100].

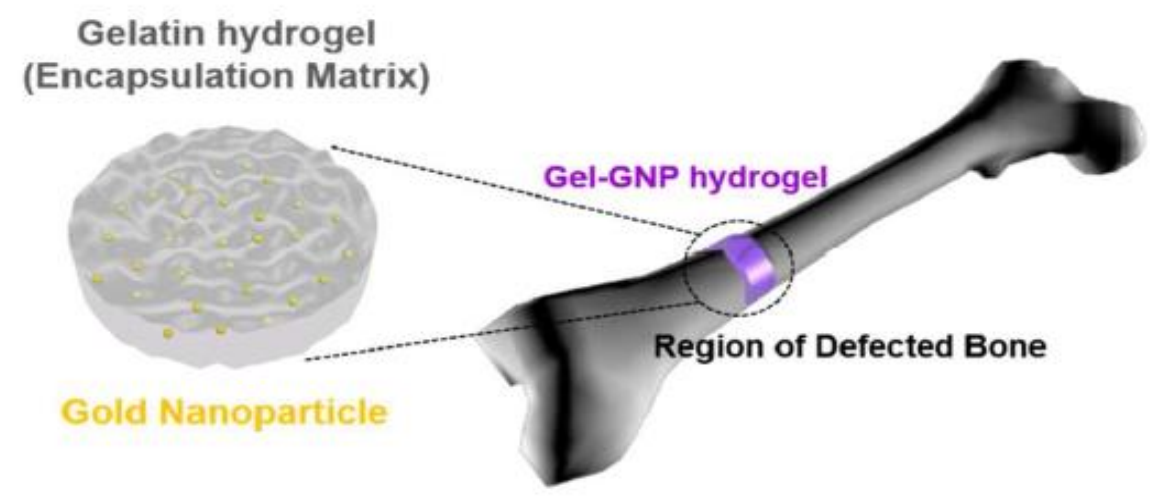

Figure 3. Schematic diagram of photo-cured gelatin hydrogel network loaded with GNP and its application for treating bone defects. Reproduced with permission from [50] @ 2014 The Royal Society of Chemistry

MNPs are also considered in treating cardiac diseases. AuNPs impregnated in BSA/PVA scaffold exhibits cardiomyogenic differentiation properties that are favorable in treating myocardial infarction. MSCs cultured on nanofiber construct (BSA/PVA) containing AuNPs allow cardiomyogenic differentiation. Being AuNP a natural cross-linker gets attached to BSA via cysteines. The cell proliferation rate increased day-by-day and reached a maximum on the $14^{\text {th }}$ day. The enhanced proliferation arises from the interaction of the hydrophilic surface of BSA with plasma proteins. The cell proliferation started lowering from day 21 due to the completion of differentiation. The cardiomyogenic differentiation of MSCs was further confirmed by the marker proteins. All cells expressed CD90, which is a marker protein of MSCs, while the differentiated cells expressed cardiac-specific actinin and troponin. The intensity of cardiac proteins from the samples with AuNPs loaded scaffold was higher than other sample tissues; revealed the significant differentiation of MSCs to cardiomyocytes in the presence of AuNPs [51].

\section{Bioimaging}

Diagnosis of diseased tissue or area is crucial before starting therapy. NPs are also exploited in the field of in vivo detection, which contributes to targeted therapy. NPs gained much attention in this field on the account of their particle size and optical properties. In consideration of the toxicity and stability issues associated with organic and inorganic fluorescent probes, the development of safer alternative agent is inevitable. MNPs having specific optical properties (surface plasmon resonance, surface-enhanced Raman scattering, and 
photostability) and non-cytotoxicity are beneficial in bioimaging applications [101-106].

Curcumin, a natural fluorescent agent present in Curcuma longa can be used in combination with MNPs for bioimaging. Curcuma longa tuber powder was used with metal precursors forming fluorescent MNPs with varying fluorescence intensity. Among the three metals used (iron, copper, and silver) AgNPs exhibited higher fluorescence. Curcumin acts as a reducing and capping agent that results in the formation of fluorescent MNPs. The developed fluorescent MNPs are biocompatible since only less than $1 \%$ of hemolysis was observed during hemolysis assay. After $6 \mathrm{~h}$ exposure of human lung cancer cells A549 with MNPs, fluorescence emitted by the cells indicated the penetration of MNPs into the cells, while samples without MNPs remained colorless [52].

Being $\mathrm{Zn}$ a trace element present in our body is cost-effective having a good safety profile with no pollution issues. ZnNPs, having good photostability and photoluminescence properties, are suitable for bioimaging. For maintaining the luminescence property under in vivo conditions, the inclusion of a protective coating is necessary for ZnNPs [101-103].

Folate receptor overexpression in cancer cells can be utilized for targeting and bioimaging. The inclusion of folic acid during the development of $\mathrm{Cu}$ nanoclusters leads to the functionalization of $\mathrm{Cu}$ nanoclusters with folic acid that allows effective targeting. The $\mathrm{Cu}$ nanocluster thus formed emits blue fluorescence $(440 \mathrm{~nm})$ upon excitation at 270 and $350 \mathrm{~nm}$. From the cell uptake study with HeLa cells and A549 cells, it was concluded that the fluorescence intensity increases with the increase in the concentration of $\mathrm{Cu}$ nanoclusters and the concentration of $\mathrm{Cu}$ in HeLa cells is 6.5 fold greater than A549 cells; since HeLa cells contains folate receptors that ensures folate mediated uptake of $\mathrm{Cu}$ nanoclusters [54]. Multicolor fluorescent ZnNPs were developed by treating leukemia cells with $\mathrm{Zn}$ solution. ZnNPs so formed emits green, red, and yellow fluorescence with a microvesicle covering and good biocompatibility. The presence of microvesicle coating helped in reducing the toxicity and improving the biocompatibility. The in vivo studies carried in tumor-bearing nude mice after attaching folic acid and human VEGF antibody have shown the accumulation of MNPs in the tumor site [107].

Macrophages loaded with Au nanoshells and fluorescent microspheres can be effectively used for theranostic purposes in brain metastases of breast cancer. After the systemic administration of the developed system into mice with brain metastases, loaded macrophages effectively crossed the BBB and reached the metastases thereby releasing the $\mathrm{Au}$ nanoshells. Meanwhile, green fluorescence was observed in the metastases indicating the crossing of BBB [108].

Pd nanoclusters emit green fluorescence at 500 $\mathrm{nm}$ with an excitation wavelength of $420 \mathrm{~nm}$. Their biocompatibility is ensured by the use of L-ascorbic acid and DL-methionine in their synthesis. The presence of amino acid groups on the surface of $\mathrm{Pd}$ nanoclusters protects them from agglomerationinduced cytotoxicity. In the in vitro studies with HeLa cells, the Pd nanoclusters were found to be entered into the cytoplasm and nucleus, thereby emitting green fluorescence. The fluorescence intensity increased with the increase in exposure time with HeLa cells [109].

\section{Photodynamic and photothermal therapies}

These therapies involve the use of photosensitizers and light of a particular wavelength for therapeutic purposes. In photothermal therapy, tumor cells are destroyed by the application of heat developed by electromagnetic radiation [110]. Polymer (biotinPEG-b-PLL) coated Au nanorods loaded with anticancer drug DOX via a thermosensitive AZO linkage (azobis(N-(2-carboxyethyl)-2methylpropionamidine) was reported for such a purpose. The introduction of biotin ligand in the polymer shell provides targeting effectiveness. Coating of $\mathrm{Au}$ nanorods with polymer shell was achieved through lipoic acid. The presence of PEG moiety helps in the escape of RES system and prolongs the circulation half-life. Upon exposure with near IR light, - AZO linkage was broken down due to the buildup of heat and effective release of DOX occurs. Active and passive tumor targeting is achieved by this drug delivery system [111]. PEGylated Au nanorods were functionalized with monoclonal antibody cetuximab for targeted delivery and tumor growth blockage. Surface modification of NP enhanced the biocompatibility; there was a 10fold reduction in cytotoxicity than the unmodified 
one. After the exposure of near IR radiation to tumorbearing xenograft mice injected with surface modified $\mathrm{Au}$ nanorods significant cell death was observed than that in control without exposure to IR [112]. In another study, $\mathrm{Au} @ \mathrm{Ag} / \mathrm{Au} \mathrm{NPs}$ in combination with self-assembled activatable aptamer probes (AAPs) formed activatable theranostic nanoprobe (ATNP). On injecting A549 cancer cell implanted nude mice with ATNP, aptamer mediated tumor targeting was achieved and the aptamer at the tumor site underwent a conformational change, which resulted in fluorescence emission since the AAP part contained fluorophore also. The fluorescence intensity at the tumor site reached a maximum after a particular period and the exposure of this region with near IR resulted in tumor necrosis [15].

The photodynamic property of $\mathrm{TiO}_{2} \mathrm{NPs}$ and zinc phthalocyanine can be combined for synergistic action. The hybrid formed from zinc phthalocyanine and $\mathrm{TiO}_{2} \quad \mathrm{NPs}\left(\mathrm{ZnPc} @ \mathrm{TiO}_{2}\right)$ [113] acts as a photosensitizer and drug delivery carrier. The problem of selectivity and cellular uptake was overcome by surface modification of hybrid with folic acid. Since folic acid receptors are overexpressed in most of the cancer cells, this allows effective targeting of the hybrid. The drug DOX was loaded effectively into the nanostructure via electrostatic interaction. The in vitro studies with HeLa cells and normal fibroblast cells (MSU-1.1) shows that the cells after near IR irradiation show a significant reduction in cell viability observed (i.e., less than 90\%) while the normal cells remain unaffected. This ensures the selective activity of the hybrid in cancer cells. The drug-loaded hybrid was more cytotoxic than the hybrid without DOX and a red fluorescence observed in the cytoplasm due to the distribution of DOX. Near IR exposure further enhanced the cytotoxicity of drug-loaded hybrid and the cell viability got reduced to less than $2 \%$ [113].

A dual functional nano-agent was developed by Tang et al. for cancer therapy. They utilized Pd nanosheets in their ultrasmall size for drug delivery and photothermal therapy. The obtained nanosheets were $\mathrm{pH}$-responsive, which on loading with DOX produced a synergistic anticancer action. They can be effectively excreted through the renal system via glutathione conjugation. During the in vivo studies in 4T1 tumor-bearing Balb/c mice, a significant rise in temperature (up to $58.5^{\circ} \mathrm{C}$ ) at the tumor site was observed after NIR irradiation in the group treated with nano-agent, while in the group with saline injection produced only a small rise in temperature (up to $35.8^{\circ} \mathrm{C}$ ) [114].

\section{PROSPECTS AND CONCLUSIONS}

The area of non-iron MNP is still an expanding area of nanotechnology. The fascinating thing about noniron MNP is its properties itself. Their unique optical, magnetic, chemical, and biological properties are attracting researchers. The availability of the green method of synthesis further enhanced the feasibility.

Non-iron MNPs are capable of meeting the limitations of existing therapies such as antimicrobial drug resistance, early cancer detection, etc. Even though extensive research has been carried, it is mainly focused on cancer therapy and further exploration is required in other diseases such as AIDS, diabetes, brain disorders, etc. A deep understanding of pharmacokinetic features is imperative for obtaining a clear therapeutic and pharmacological profile, which contribute to more relevant utilization of MNPs. Inorganic NPs cause toxicity by inducing ROS or by interfering with the intracellular signaling pathways and genotoxicity [115]. Before developing an efficient system involving MNPs, their toxicity issue must be focused, since some modifications such as surface coating can bring about large changes that would result in a safer alternative.

Currently, the problem in the therapeutic application of non-iron NP is the lack of sufficient in vivo experiments, i.e., human and animal models, which are important in determining the biological behavior of non-iron MNPs. Since the properties of MNPs vary with size, shape, environment, a proper investigation is necessary for exploring the benefits of MNP in biomedicine.

\section{COMPETING INTEREST}

The authors have no competing interests to declare.

\section{FUNDING}

This work did not receive any funding. 


\section{REFERENCES}

1. K. McNamara, S.A.M. Tofail, Nanoparticles in biomedical applications, Adv. Phys. X. 2 (2017) 54 88. doi:10.1080/23746149.2016.1254570.

2. V. Mody, R. Siwale, A. Singh, H. Mody, Introduction to metallic nanoparticles, J. Pharm. Bioallied Sci. 2 (2010) 282-289. doi:10.4103/09757406.72127.

3. A.K. Barui, S. Das, C.R. Patra, 10 - Biomedical applications of green-synthesized metal nanoparticles using polysaccharides, in: S. Maiti, S.B.T.-F.P. for B.A. Jana (Eds.), Woodhead Publishing, 2019: pp. 329-355. doi:https://doi.org/10.1016/B978-0-08-1025550.00010-8.

4. S. Kamboj, S. Bala, A.B. Nair, Solid lipid nanoparticles: an effective lipid based technology for poorly water soluble drugs, Int J Pharm Sci Rev Res. 5 (2010) 78-90.

5. B.A. Camacho-Flores, O. Martínez-Álvarez, M.C. Arenas-Arrocena, R. Garcia-Contreras, L. ArguetaFigueroa, J. de la Fuente-Hernández, L.S. AcostaTorres, Copper: Synthesis Techniques in Nanoscale and Powerful Application as an Antimicrobial Agent, J. Nanomater. 2015 (2015) 415238. doi:10.1155/2015/415238.

6. S.O. Aisida, P.A. Akpa, I. Ahmad, T. Zhao, M. Maaza, F.I. Ezema, Bio-inspired encapsulation and functionalization of iron oxide nanoparticles for biomedical applications, Eur. Polym. J. 122 (2020) 109371.

doi:https://doi.org/10.1016/j.eurpolymj.2019.10937 1.

7. M.D. Mauricio, S. Guerra-Ojeda, P. Marchio, S.L. Valles, M. Aldasoro, I. Escribano-Lopez, J.R. Herance, M. Rocha, J.M. Vila, V.M. Victor, Nanoparticles in Medicine: A Focus on Vascular Oxidative Stress, Oxid. Med. Cell. Longev. 2018 (2018) 6231482. doi:10.1155/2018/6231482.

8. L. Hernández-Morales, H. Espinoza-Gómez, L.Z. Flores-López, E.L. Sotelo-Barrera, A. NúñezRivera, R.D. Cadena-Nava, G. Alonso-Núñez, K.A. Espinoza, Study of the green synthesis of silver nanoparticles using a natural extract of dark or white Salvia hispanica L. seeds and their antibacterial application, Appl. Surf. Sci. 489 (2019) 952-961. doi:https://doi.org/10.1016/ j.apsusc. 2019.06.031.

9. H. Bahadar, F. Maqbool, K. Niaz, M. Abdollahi, Toxicity of Nanoparticles and an Overview of
Current Experimental Models, Iran. Biomed. J. 20 (2016) 1-11. doi:10.7508/ibj.2016.01.001.

10. D. Pedone, M. Moglianetti, E. De Luca, G. Bardi, P.P. Pompa, Platinum nanoparticles in nanobiomedicine., Chem. Soc. Rev. 46 (2017) 49514975. doi:10.1039/c7cs00152e.

11. L.-H. Peng, J. Niu, C.-Z. Zhang, W. Yu, J.-H. Wu, Y.-H. Shan, X.-R. Wang, Y.-Q. Shen, Z.-W. Mao, W.-Q. Liang, J.-Q. Gao, TAT conjugated cationic noble metal nanoparticles for gene delivery to epidermal stem cells, Biomaterials. 35 (2014) 5605$5618 . \quad$ doi:https://doi.org/10.1016/j. biomaterials.2014.03.062.

12. A.C. Anselmo, S. Mitragotri, A Review of Clinical Translation of Inorganic Nanoparticles, AAPS J. 17 (2015) 1041-1054. doi:10.1208/s12248-015-97802.

13. A.R. Rastinehad, H. Anastos, E. Wajswol, J.S. Winoker, J.P. Sfakianos, S.K. Doppalapudi, M.R. Carrick, C.J. Knauer, B. Taouli, S.C. Lewis, A.K. Tewari, J.A. Schwartz, S.E. Canfield, A.K. George, J.L. West, N.J. Halas, Gold nanoshell-localized photothermal ablation of prostate tumors in a clinical pilot device study, Proc. Natl. Acad. Sci. 116 (2019) 18590 LP - 18596. doi:10.1073/pnas.1906929116.

14. R. Gupta, H. Xie, Nanoparticles in Daily Life: Applications, Toxicity and Regulations, J. Environ. Pathol. Toxicol. Oncol. 37 (2018) 209-230. doi:10.1615/JEnvironPatholToxicolOncol. 2018026009.

15. H. Shi, X. Ye, X. He, K. Wang, W. Cui, D. He, D. Li, X. Jia, Au@ Ag/Au nanoparticles assembled with activatable aptamer probes as smart "nano-doctors" for image-guided cancer thermotherapy., Nanoscale. 6 (2014) 8754-8761. doi:10.1039/c4nr01927j.

16. J. Jiang, J. Pi, J. Cai, The Advancing of Zinc Oxide Nanoparticles for Biomedical Applications., Bioinorg. Chem. Appl. 2018 (2018) 1062562. doi:10.1155/2018/1062562.

17. 17. A.A. Yaqoob, H. Ahmad, T. Parveen, A. Ahmad, M. Oves, I.M.I. Ismail, H.A. Qari, K. Umar, M.N. Mohamad Ibrahim, Recent Advances in Metal Decorated Nanomaterials and Their Various Biological Applications: A Review , Front. Chem. .8 (2020) 341.

18. J.P. Bullivant, S. Zhao, B.J. Willenberg, B. Kozissnik, C.D. Batich, J. Dobson, Materials characterization of Feraheme/ferumoxytol and preliminary evaluation of its potential for magnetic 
fluid hyperthermia, Int. J. Mol. Sci. 14 (2013) 17501-17510. doi:10.3390/ijms 140917501.

19. H.E. Daldrup-Link, Ten Things You Might Not Know about Iron Oxide Nanoparticles, Radiology. 284 (2017) 616-629. doi:10.1148/radiol.2017162759.

20. A.C. Anselmo, S. Mitragotri, Nanoparticles in the clinic, Bioeng. Transl. Med. 1 (2016) 10-29. doi:10.1002/btm2.10003.

21. A.C. Anselmo, S. Mitragotri, Nanoparticles in the clinic: An update, Bioeng. Transl. Med. 4 (2019) e10143-e10143. doi:10.1002/btm2.10143.

22. A.A. Yetisgin, S. Cetinel, M. Zuvin, A. Kosar, O. Kutlu, Therapeutic Nanoparticles and Their Targeted Delivery Applications, Mol. . 25 (2020). doi:10.3390/molecules25092193.

23. N.M. Lam, T.M. Thi, P.T. Thanh, N.H. Yen, N.H. Dan, Structure and magnetic properties of $\mathrm{Fe}-\mathrm{Co}$ nanoparticles prepared by polyol method, Phys. B, Condens. Matter. (2018) 71-75. doi:DOI:101016/jphysb201710039.

24. Y. Shi, M. Lin, X. Jiang, S. Liang, Recent Advances in FePt Nanoparticles for Biomedicine, J. Nanomater. $2015 \quad$ (2015) 467873. doi:10.1155/2015/467873.

25. I. Ban, J. Stergar, M. Drofenik, G. Ferk, D. Makovec, Synthesis of chromium-nickel nanoparticles prepared by a microemulsion method and mechanical milling., Acta Chim. Slov. 60 (2013) 750-755.

26. D. Salado-Leza, A. Traore, E. Porcel, D. Dragoe, A. Muñoz, H. Remita, G. García, S. Lacombe, RadioEnhancing Properties of Bimetallic $\mathrm{Au}: \mathrm{Pt}$ Nanoparticles: Experimental and Theoretical Evidence, Int. J. Mol. Sci. 20 (2019) 5648. doi:10.3390/ijms20225648.

27. X. Zhao, Y. Jia, R. Dong, J. Deng, H. Tang, F. Hu, S. Liu, X. Jiang, Bimetallic nanoparticles against multi-drug resistant bacteria, Chem. Commun. 56 (2020) 10918-10921. doi:10.1039/D0CC03481A.

28. A.M. Ross, T. Kennedy, D. McNulty, C.I. Leahy, D.R. Walsh, P. Murray, A.M. Grabrucker, J.J.E. Mulvihill, Comparing nanoparticles for drug delivery: The effect of physiological dispersion media on nanoparticle properties, Mater. Sci. Eng. C. $113 \quad$ (2020) 110985. doi:https://doi.org/10.1016/j.msec.2020.110985.

29. S. Gul, S.B. Khan, I.U. Rehman, M.A. Khan, M.I. Khan, A Comprehensive review of magnetic nanomaterials modern day theranostics, Front. Mater. 6 (2019) 179.

30. P. Khandel, R.K. Yadaw, D.K. Soni, L. Kanwar, S.K. Shahi, Biogenesis of metal nanoparticles and their pharmacological applications: present status and application prospects, J. Nanostructure Chem. 8 (2018) 217-254. doi:10.1007/s40097-018-0267-4.

31. Y. Yamamoto, T. Miura, Y. Nakae, T. Teranishi, M. Miyake, H. Hori, Magnetic properties of the noble metal nanoparticles protected by polymer, Phys. B Condens. Matter. 329 (2003) 1183-1184. doi:10.1016/S0921-4526(02)02102-6.

32. E. Saad, N. Farshori, M. Al-Oqail, S. Massarani, Q. Saquib, R. Wahab, J. Musarrat, M. Khan, M. Siddiqui, Anticancer Potential of Green Synthesized Silver Nanoparticles Using Extract of Nepeta deflersiana against Human Cervical Cancer Cells (HeLA), Bioinorg. Chem. Appl. 2018 (2018) 1-12. doi:10.1155/2018/9390784.

33. R. Augustine, Y.B. Dalvi, V.K. Yadu Nath, R. Varghese, V. Raghuveeran, A. Hasan, S. Thomas, N. Sandhyarani, Yttrium oxide nanoparticle loaded scaffolds with enhanced cell adhesion and vascularization for tissue engineering applications, Mater. Sci. Eng. C. 103 (2019) 109801. doi:https://doi.org/10.1016/j.msec.2019.109801.

34. Q. Wu, W. Miao, Y. Zhang, H. Gao, D. Hui, Mechanical properties of nanomaterials: A review, Nanotechnol. Rev. 9 (2020) 259-273. doi:https://doi.org/10.1515/ntrev-2020-0021.

35. D.P.S. Thakur Prasad Yadav, Ram Manohar Yadav, Mechanical Milling: a Top Down Approach for the Synthesis of Nanomaterials and Nanocomposites, Nanosci. Nanotechnol. 2 (2012) 22-48.

36. P.G. Jamkhande, N.W. Ghule, A.H. Bamer, M.G. Kalaskar, Metal nanoparticles synthesis: An overview on methods of preparation, advantages and disadvantages, and applications, J. Drug Deliv. Sci. Technol. 53 (2019) 101174.

37. Y.X. Gan, A.H. Jayatissa, Z. Yu, X. Chen, M. Li, Hydrothermal Synthesis of Nanomaterials, (2020).

38. A.B. Nair, B.E. Al-Dhubiab, J. Shah, M. Attimarad, S. Harsha, Poly (lactic acid-co-glycolic acid) Nanospheres improved the oral delivery of candesartan cilexetil, Indian J. Pharm. Educ. Res. 51 (2017) 571-579.

39. A. Kajani, Abolghasem Abbasi, Bordbar, AbdolKhalegh, Zarkesh Esfahani, Sayyed Hamid, Razmjou, Gold nanoparticles as potent anticancer 
agent: green synthesis, characterization, and in vitro study, RSC Adv. 6 (2016) 63973-63983.

40. S.S. Salem, A. Fouda, Green Synthesis of Metallic Nanoparticles and Their Prospective Biotechnological Applications: an Overview, Biol. Trace Elem. Res. (2020). doi:10.1007/s12011-02002138-3.

41. E. Sánchez-López, D. Gomes, G. Esteruelas, L. Bonilla, A.L. Lopez-Machado, R. Galindo, A. Cano, M. Espina, M. Ettcheto, A. Camins, A.M. Silva, A. Durazzo, A. Santini, M.L. Garcia, E.B. Souto, MetalBased Nanoparticles as Antimicrobial Agents: An Overview, Nanomater. $\quad 10 \quad$ (2020). doi:10.3390/nano10020292.

42. J. Singh, T. Dutta, K.-H. Kim, M. Rawat, P. Samddar, P. Kumar, 'Green' synthesis of metals and their oxide nanoparticles: applications for environmental remediation, J. Nanobiotechnology. 16 (2018) 84. doi:10.1186/s12951-018-0408-4.

43. M.A. Almalki, A.Y.Z. Khalifa, Silver nanoparticles synthesis from Bacillus sp KFU36 and its anticancer effect in breast cancer MCF-7 cells via induction of apoptotic mechanism, J. Photochem. Photobiol. B Biol. $204 \quad 111786$. doi:https://doi.org/10.1016/j.jphotobiol.2020.11178 6.

44. R.C. de Souza, L.U. Haberbeck, H.G. Riella, D.H.B. Ribeiro, B.A.M. Carciofi, ANTIBACTERIAL ACTIVITY OF ZINC OXIDE NANOPARTICLES SYNTHESIZED BY SOLOCHEMICAL PROCESS , Brazilian J. Chem. Eng. . 36 (2019) 885-893.

45. A. Hasan, M. Morshed, A. Memic, S. Hassan, T.J. Webster, H.E.-S. Marei, Nanoparticles in tissue engineering: applications, challenges and prospects, Int. J. Nanomedicine. 13 (2018) 5637-5655. doi:10.2147/IJN.S153758.

46. R.A. Hamouda, M.H. Hussein, R.A. Abo-elmagd, S.S. Bawazir, Synthesis and biological characterization of silver nanoparticles derived from the cyanobacterium Oscillatoria limnetica, Sci. Rep. 9 (2019) 13071. doi:10.1038/s41598-019-49444-y.

47. Z. Assadi, G. Emtiazi, A. Zarrabi, Hyperbranched polyglycerol coated on copper oxide nanoparticles as a novel core-shell nano-carrier hydrophilic drug delivery model, J. Mol. Liq. 250 (2018) 375-380. doi:https://doi.org/10.1016/j.molliq.2017.12.031.

48. S.-B. Ghaffari, M.-H. Sarrafzadeh, M. Salami, M.R. Khorramizadeh, A pH-sensitive delivery system based on $\mathrm{N}$-succinyl chitosan-ZnO nanoparticles for improving antibacterial and anticancer activities of curcumin, Int. J. Biol. Macromol. 151 (2020) 428440 .

doi:https://doi.org/10.1016/j.ijbiomac.2020.02.141.

49. G.R. Dhanya, D.S. Caroline, M.R. Rekha, K. Sreenivasan, Histidine and arginine conjugated starch-PEI and its corresponding gold nanoparticles for gene delivery., Int. J. Biol. Macromol. 120 (2018) 999-1008. doi:10.1016/j.ijbiomac.2018.08.142.

50. dong nyoung Heo, W.-K. Ko, M.S. Bae, J. Lee, D.W. Lee, W. Byun, E. Kim, B.-Y. Jung, I.K. Kwon, Enhanced bone regeneration with a gold nanoparticle-hydrogel complex, J. Mater. Chem. B. 2 (2014). doi:10.1039/C3TB21246G.

51. R. Ravichandran, R. Sridhar, J.R. Venugopal, S. Sundarrajan, S. Mukherjee, S. Ramakrishna, Gold nanoparticle loaded hybrid nanofibers for cardiogenic differentiation of stem cells for infarcted myocardium regeneration., Macromol. Biosci. 14 (2014) 515-525. doi:10.1002/mabi.201300407.

52. R. Sankar, P.K.S.M. Rahman, K. Varunkumar, C. Anusha, A. Kalaiarasi, K.S. Shivashangari, V. Ravikumar, Facile synthesis of Curcuma longa tuber powder engineered metal nanoparticles for bioimaging applications, J. Mol. Struct. 1129 (2017) 8-16.

doi:https://doi.org/10.1016/j.molstruc.2016.09.054.

53. S. Thangudu, P. Kalluru, R. Vankayala, Preparation, Cytotoxicity, and In Vitro Bioimaging of Water Soluble and Highly Fluorescent Palladium Nanoclusters, Bioengineering. 7 (2020) 20. doi:10.3390/bioengineering7010020.

54. J.-M. Xia, X. Wei, X.-W. Chen, Y. Shu, J.-H. Wang, Folic acid modified copper nanoclusters for fluorescent imaging of cancer cells with overexpressed folate receptor, Microchim. Acta. 185 (2018) 205. doi:10.1007/s00604-018-2743-4.

55. A. Sukhanova, S. Bozrova, P. Sokolov, M. Berestovoy, A. Karaulov, I. Nabiev, Dependence of Nanoparticle Toxicity on Their Physical and Chemical Properties, Nanoscale Res. Lett. 13 (2018) 44. doi:10.1186/s11671-018-2457-X.

56. Z.T. Yao Y, Zang Y, Qu J, Tang M, The Toxicity Of Metallic Nanoparticles On Liver: The Subcellular Damages, Mechanisms, And Outcomes., Int J Nanomedicine. 14 (2019) 8787-8804.

57. Y.-H. Luo, L.W. Chang, P. Lin, Metal-Based Nanoparticles and the Immune System: Activation, Inflammation, and Potential Applications, Biomed Res. Int. $2015 \quad$ (2015) 143720. doi:10.1155/2015/143720. 
58. A.M. Schrand, M.F. Rahman, S.M. Hussain, J.J. Schlager, D.A. Smith, A.F. Syed, Metal-based nanoparticles and their toxicity assessment, WIREs Nanomedicine and Nanobiotechnology. 2 (2010) 544-568. doi:10.1002/wnan.103.

59. X. Li, L. Wang, Y. Fan, Q. Feng, F. Cui, Biocompatibility and Toxicity of Nanoparticles and Nanotubes, J. Nanomater. 2012 (2012) 548389. doi:10.1155/2012/548389.

60. S. Jomini, S. Charles, V. Fessard, E. Bigorgne, C. Rousselle, C. Michel, Assessment of the in vitro genotoxicity of $\mathrm{TiO} 2$ nanoparticles in a regulatory context, Nanotoxicology. $12 \quad$ (2018). doi:10.1080/17435390.2018.1451567.

61. G. V Vimbela, S.M. Ngo, C. Fraze, L. Yang, D.A. Stout, Antibacterial properties and toxicity from metallic nanomaterials., Int. J. Nanomedicine. 12 (2017) 3941-3965. doi:10.2147/IJN.S134526.

62. Y. Pan, S. Neuss, A. Leifert, M. Fischler, F. Wen, U. Simon, G. Schmid, W. Brandau, W. Jahnen-Dechent, Size-dependent cytotoxicity of gold nanoparticles., Small. $\quad 3 \quad$ (2007) 1941-1949. doi:10.1002/smll.200700378.

63. A.B. Nair, A. Kaushik, M. Attimarad, B.E. AlDhubiab, Enhanced oral bioavailability of calcium using bovine serum albumin microspheres, Drug Deliv. 19 (2012) 277-285.

64. C. Carnovale, G. Bryant, R. Shukla, V. Bansal, Identifying Trends in Gold Nanoparticle Toxicity and Uptake: Size, Shape, Capping Ligand, and Biological Corona, ACS Omega. 4 (2019) 242-256. doi:10.1021/acsomega.8b03227.

65. K. Kawata, M. Osawa, S. Okabe, In Vitro Toxicity of Silver Nanoparticles at Noncytotoxic Doses to HepG2 Human Hepatoma Cells, Environ. Sci. Technol. 43 (2009) 6046-6051. doi:10.1021/es900754q.

66. S. Hackenberg, A. Scherzed, M. Kessler, S. Hummel, A. Technau, K. Froelich, C. Ginzkey, C. Koehler, R. Hagen, N. Kleinsasser, Silver nanoparticles: evaluation of DNA damage, toxicity and functional impairment in human mesenchymal stem cells., Toxicol. Lett. 201 (2011) 27-33. doi:10.1016/j.toxlet.2010.12.001.

67. A.S. Takamiya, D.R. Monteiro, D.G. Bernabé, L.F. Gorup, E.R. Camargo, J.E. Gomes-Filho, S.H.P. Oliveira, D.B. Barbosa, In Vitro and In Vivo Toxicity Evaluation of Colloidal Silver Nanoparticles Used in Endodontic Treatments., J.
Endod. $\quad 42 \quad$ (2016) 953-960. doi:10.1016/j.joen.2016.03.014.

68. M. Horie, K. Nishio, K. Fujita, S. Endoh, A. Miyauchi, Y. Saito, H. Iwahashi, K. Yamamoto, H. Murayama, H. Nakano, N. Nanashima, E. Niki, Y. Yoshida, Protein Adsorption of Ultrafine Metal Oxide and Its Influence on Cytotoxicity toward Cultured Cells, Chem. Res. Toxicol. 22 (2009) 543553. doi:10.1021/tx800289z.

69. J.C.K. Lai, M.B. Lai, S. Jandhyam, V. V Dukhande, A. Bhushan, C.K. Daniels, S.W. Leung, Exposure to titanium dioxide and other metallic oxide nanoparticles induces cytotoxicity on human neural cells and fibroblasts, Int. J. Nanomedicine. 3 (2008) 533-545. doi:10.2147/ijn.s3234.

70. H.A. Jeng, J. Swanson, Toxicity of metal oxide nanoparticles in mammalian cells., J. Environ. Sci. Heal. Part A, Toxic/Hazardous Subst. Environ. Eng. 41 (2006) 2699-2711. doi:10.1080/10934520600966177.

71. D. Sahu, M. Kannan, R. Vijayaraghavan, T. Anand, F. Khanum, Nanosized Zinc Oxide Induces Toxicity in Human Lung Cells, ISRN Toxicol. 2013 (2013) 316075. doi:10.1155/2013/316075.

72. M. Ahamed, M.A. Siddiqui, M.J. Akhtar, I. Ahmad, A.B. Pant, H.A. Alhadlaq, Genotoxic potential of copper oxide nanoparticles in human lung epithelial cells., Biochem. Biophys. Res. Commun. 396 (2010) 578-583. doi:10.1016/j.bbrc.2010.04.156.

73. S.N. Harsha, B.E. Aldhubiab, A.B. Nair, I.A. Alhaider, M. Attimarad, K.N. Venugopala, S. Srinivasan, N. Gangadhar, A.H. Asif, Nanoparticle formulation by Büchi B-90 Nano Spray Dryer for oral mucoadhesion, Drug Des. Devel. Ther. 9 (2015) 273.

74. B.E. Al-Dhubiab, A.B. Nair, R. Kumria, M. Attimarad, S. Harsha, Formulation and evaluation of nano based drug delivery system for the buccal delivery of acyclovir, Colloids Surfaces B Biointerfaces. 136 (2015) 878-884.

75. K. Gold, B. Slay, M. Knackstedt, A.K. Gaharwar, Antimicrobial Activity of Metal and Metal-Oxide Based Nanoparticles, Adv. Ther. 1 (2018) 1700033. doi:10.1002/adtp.201700033.

76. S.M. Dizaj, F. Lotfipour, M. Barzegar-Jalali, M.H. Zarrintan, K. Adibkia, Antimicrobial activity of the metals and metal oxide nanoparticles., Mater. Sci. Eng. C. Mater. Biol. Appl. 44 (2014) 278-284. doi:10.1016/j.msec.2014.08.031. 
77. L. Wang, C. Hu, L. Shao, The antimicrobial activity of nanoparticles: present situation and prospects for the future., Int. J. Nanomedicine. 12 (2017) $1227-$ 1249. doi:10.2147/IJN.S121956.

78. H. Ji, S. Zhou, Y. Fu, Y. Wang, J. Mi, T. Lu, X. Wang, C. Lü, Size-controllable preparation and antibacterial mechanism of thermo-responsive copolymer-stabilized silver nanoparticles with high antimicrobial activity, Mater. Sci. Eng. C. 110 (2020) 110735. doi:10.1016/j.msec.2020.110735.

79. R. Kalaivani, M. Maruthupandy, T. Muneeswaran, A. Hameedha Beevi, M. Anand, C.M. Ramakritinan, A.K. Kumaraguru, Synthesis of chitosan mediated silver nanoparticles (Ag NPs) for potential antimicrobial applications, Front. Lab. Med. 2 (2018) $30-35$. doi:https://doi.org/10.1016/j.flm.2018.04.002.

80. Y. Ren, H. Yang, T. Wang, C. Wang, Bio-synthesis of silver nanoparticles with antibacterial activity, Mater. Chem. Phys. 235 (2019) 121746. doi:https://doi.org/10.1016/j.matchemphys.2019.12 1746.

81. S. Akter, M.A. Huq, Biologically rapid synthesis of silver nanoparticles by Sphingobium sp. MAH-11T and their antibacterial activity and mechanisms investigation against drug-resistant pathogenic microbes, Artif. Cells, Nanomedicine, Biotechnol. 48 (2020) 672-682. doi:10.1080/21691401.2020.1730390.

82. A.A. Mujeeb, N.A. Khan, F. Jamal, K.F.B. Alam, H. Saeed, S. Kazmi, A.W.F. Alshameri, M. Kashif, I. Ghazi, M. Owais, Olax scandens mediated biogenic synthesis of $\mathrm{Ag}-\mathrm{Cu}$ nanocomposites: potential against inhibition of drug-resistant microbes, Front. Chem. 8 (2020).

83. Z. Azam, A. Ayaz, M. Younas, Z. Qureshi, B. Arshad, W. Zaman, F. Ullah, M.Q. Nasar, S. Bahadur, M.M. Irfan, S. Hussain, S. Saqib, Microbial synthesized cadmium oxide nanoparticles induce oxidative stress and protein leakage in bacterial cells, Microb. Pathog. $144 \quad$ (2020) 104188. doi:https://doi.org/10.1016/j.micpath.2020.104188.

84. J.N. Payne, H.K. Waghwani, M.G. Connor, W. Hamilton, S. Tockstein, H. Moolani, F. Chavda, V. Badwaik, M.B. Lawrenz, R. Dakshinamurthy, Novel Synthesis of Kanamycin Conjugated Gold Nanoparticles with Potent Antibacterial Activity, Front. Microbiol. 7 (2016) 607. doi:10.3389/fmicb.2016.00607.
85. B.E. Al-Dhubiab, A.B. Nair, R. Kumria, M. Attimarad, S. Harsha, Development and evaluation of buccal films impregnated with selegiline-loaded nanospheres, Drug Deliv. 23 (2016) 2154-2162.

86. S. Yaqoob, R. Adnan, R. Khan, M. Rashid, Gold, Silver, and Palladium Nanoparticles: A Chemical Tool for Biomedical Applications, Front. Chem. 8 (2020). doi:10.3389/fchem.2020.00376.

87. J. Bai Aswathanarayan, R. Rai Vittal, U. Muddegowda, Anticancer activity of metal nanoparticles and their peptide conjugates against human colon adenorectal carcinoma cells, Artif. Cells, Nanomedicine, Biotechnol. 46 (2018) 14441451. doi:10.1080/21691401.2017. 1373655.

88. S.A. Loutfy, N.A. Al-Ansary, N.T. Abdel-Ghani, A.R. Hamed, M.B. Mohamed, J.D. Craik, T.A.S. Eldin, A.M. Abdellah, Y. Hussein, M.T.M. Hasanin, S.E.I. Elbehairi, Anti-proliferative Activities of Metallic Nanoparticles in an in Vitro Breast Cancer Model., Asian Pac. J. Cancer Prev. 16 (2015) 60396046. doi:10.7314/apjcp. 2015.16.14.6039.

89. D. Lombardo, M.A. Kiselev, M.T. Caccamo, Smart Nanoparticles for Drug Delivery Application: Development of Versatile Nanocarrier Platforms in Biotechnology and Nanomedicine, J. Nanomater. 2019 (2019) 3702518. doi:10.1155/2019/3702518.

90. M.F. Sanad, A.E. Shalan, S.M. Bazid, E.S.A. Serea, E.M. Hashem, S. Nabih, M.A. Ahsan, A graphene gold nanocomposite-based 5-FU drug and the enhancement of the MCF-7 cell line treatment, RSC Adv. 9 (2019) 31021-31029.

91. D. George, P.U. Maheswari, K.M.M.S. Begum, Chitosan-cellulose hydrogel conjugated with Lhistidine and zinc oxide nanoparticles for sustained drug delivery: Kinetics and in-vitro biological studies, Carbohydr. Polym. 236 (2020) 116101. doi:https://doi.org/10.1016/j.carbpol.2020.116101.

92. J. Hitchcock, A.L. White, N. Hondow, T.A. Hughes, H. Dupont, S. Biggs, O.J. Cayre, Metal-shell nanocapsules for the delivery of cancer drugs, J. Colloid Interface Sci. 567 (2020) 171-180. doi:https://doi.org/10.1016/j.jcis.2019.12.018.

93. P.A. Fatematossadat, M. Mohammadi, S.E. Roozmeh, Fe@(Au/Ag)n $(\mathrm{n}=1,12,54)$ core-shell nanoparticles as effective drug delivery vehicles for anti-cancer drugs: The computational study, J. Mol. Graph. Model. $90 \quad$ (2019) 33-41. doi:https://doi.org/10.1016/j.jmgm.2019.03.020.

94. H. Li, S. Pan, P. Xia, Y. Chang, C. Fu, W. Kong, Z. Yu, K. Wang, X. Yang, Z. Qi, Advances in the 
application of gold nanoparticles in bone tissue engineering, J. Biol. Eng. 14 (2020) 14 . doi:10.1186/s13036-020-00236-3.

95. G. Janarthanan, I. Noh, Recent trends in metal ion based hydrogel biomaterials for tissue engineering and other biomedical applications, J. Mater. Sci. Technol. (2020). doi:https://doi.org/10.1016/j.jmst.2020.02.052.

96. M. Yadid, R. Feiner, T. Dvir, Gold NanoparticleIntegrated Scaffolds for Tissue Engineering and Regenerative Medicine, Nano Lett. 19 (2019) 2198 2206. doi:10.1021/acs.nanolett.9b00472.

97. C.M. Srivastava, R. Purwar, A.P. Gupta, Enhanced potential of biomimetic, silver nanoparticles functionalized Antheraea mylitta (tasar) silk fibroin nanofibrous mats for skin tissue engineering, Int. J. Biol. Macromol. $130 \quad$ (2019) 437-453. doi:https://doi.org/10.1016/j. ijbiomac.2018.12.255.

98. Y. Jiang, N. Krishnan, J. Heo, R.H. Fang, L. Zhang, Nanoparticle-hydrogel superstructures for biomedical applications, J. Control. Release. 324 (2020) 505-521. doi:https://doi.org/10. 1016/j. jconrel.2020.05.041.

99. F.H. Zulkifli, F.S.J. Hussain, S.S. Zeyohannes, M.S.B.A. Rasad, M.M. Yusuff, A facile synthesis method of hydroxyethyl cellulose-silver nanoparticle scaffolds for skin tissue engineering applications, Mater. Sci. Eng. C. 79 (2017) 151-160. doi:https://doi.org/10.1016/j.msec.2017.05.028.

100. F.H. Zulkifli, N.A.M. Rani, F. Shahitha, Carboxymethyl cellulose nanofibres impregnated with silver nanoparticles for tissue engineering applications, Mater. Today Proc. 16 (2019) 17151721. doi:https://doi.org/10.1016/j.matpr.2019.06.041.

101. Y. Patel, S. Saha, C. DiMarzio, D. O’Malley, D. Nagesha, S. Sridhar, Metallic nanoparticles for biomedical imaging, in: 2009 IEEE Int. Symp. Biomed. Imaging From Nano to Macro, 2009: pp. 759-762. doi:10.1109/ISBI.2009.5193160.

102. H.-M. Xiong, ChemInform Abstract: ZnO Nanoparticles Applied to Bioimaging and Drug Delivery, Adv. Mater. 25 (2013) 5329-5335. doi:10.1002/adma.201301732.

103. K. Senthilkumar, O. Senthilkumar, K. Yamauchi, M. Sato, S. Morito, T. Ohba, M. Nakamura, Y. Fujita, Preparation of $\mathrm{ZnO}$ nanoparticles for bio-imaging applications, Phys. Status Solidi. 246 (2009) 885888. doi:10.1002/pssb.200880606.
104. O. Wolfbeis, An overview of nanoparticles commonly used in fluorescent bioimaging, Chem. Soc. Rev. 44 (2015). doi:10.1039/c4cs00392f.

105. S.K. Nune, P. Gunda, P.K. Thallapally, Y.-Y. Lin, M.L. Forrest, C.J. Berkland, Nanoparticles for biomedical imaging, Expert Opin. Drug Deliv. 6 (2009)

1175-1194. doi:10.1517/17425240903229031.

106. I. Khan, K. Saeed, I. Khan, Nanoparticles: Properties, applications and toxicities, Arab. J. Chem. $12 \quad$ (2019) 908-931. doi:https://doi.org/10.1016/j.arabjc.2017.05.011.

107. Y. Kang, Y.-Z. Wu, X. Hu, X. Xu, J. Sun, R. Geng, T. Huang, X. Liu, Y. Ma, Y. Chen, Q. Wan, X. Qi, G. Zhang, X. Zhao, X. Zeng, Multicolor bioimaging with biosynthetic zinc nanoparticles and their application in tumor detection, Sci. Rep. 7 (2017) 45313. doi:10.1038/srep45313.

108. M.-R. Choi, R. Bardhan, K.J. Stanton-Maxey, S. Badve, H. Nakshatri, K.M. Stantz, N. Cao, N.J. Halas, S.E. Clare, Delivery of nanoparticles to brain metastases of breast cancer using a cellular Trojan horse., Cancer Nanotechnol. 3 (2012) 47-54. doi:10.1007/s12645-012-0029-9.

109. V.R. No TitThangudu S, Kalluru P, Preparation, Cytotoxicity, and In Vitro Bioimaging of Water Soluble and Highly Fluorescent Palladium Nanoclusters, Bioengineering. 7(1) (n.d.).

110. Z. Bao, X. Liu, Y. Liu, H. Liu, K. Zhao, Nearinfrared light-responsive inorganic nanomaterials for photothermal therapy, Asian J. Pharm. Sci. 11 (2016) 349-364.

doi:https://doi.org/10.1016/j.ajps.2015.11.123.

111. W.-H. Chen, C.-X. Yang, W.-X. Qiu, G.-F. Luo, H.Z. Jia, Q. Lei, X.-Y. Wang, G. Liu, R.-X. Zhuo, X.Z. Zhang, Multifunctional Theranostic Nanoplatform for Cancer Combined Therapy Based on Gold Nanorods, Adv. Healthc. Mater. 4 (2015) 2247-2259. doi:10.1002/adhm.201500453.

112. J. Choi, J. Yang, D. Bang, J. Park, J.-S. Suh, Y.-M. Huh, S. Haam, Targetable gold nanorods for epithelial cancer therapy guided by near-IR absorption imaging., Small. 8 (2012) 746-753. doi:10.1002/smll.201101789.

113. D. Flak, L. Yate, G. Nowaczyk, S. Jurga, Hybrid ZnPc@TiO2 nanostructures for targeted photodynamic therapy, bioimaging and doxorubicin delivery, Mater. Sci. Eng. C. 78 (2017). doi:10.1016/j.msec.2017.04.107. 
114. S. Tang, M. Chen, N. Zheng, Multifunctional ultrasmall Pd nanosheets for enhanced near-infrared photothermal therapy and chemotherapy of cancer, Nano Res. 8 (2015) 165-174. doi:10.1007/s12274014-0605-X.

115. S.J. Soenen, P. Rivera-Gil, J.-M. Montenegro, W.J. Parak, S.C. De Smedt, K. Braeckmans, Cellular toxicity of inorganic nanoparticles: Common aspects and guidelines for improved nanotoxicity evaluation, Nano Today. 6 (2011) 446-465. doi:https://doi.org/10.1016/j. nantod.2011.08.001. 